\title{
Depressed REM Sleep Behavior Disorder Patients Are Less Likely to Recall Enacted Dreams than Non-Depressed Ones
}

\author{
Hyeong Gon Lee, Jae Won Choi, Yu Jin Lee, and Do-Un Jeong ${ }^{\bowtie}$ \\ Department of Psychiatry and Center for Sleep and Chronobiology, Seoul National University Hospital, Seoul, Republic of Korea
}

\begin{abstract}
Objective REM sleep behavior disorder (RBD) is associated with psychiatric symptoms, such as anxiety and alexithymia. However, only a few studies on the relationship between depression and RBD have been published. In this study, we investigated the occurrence of depression and associated factors in patients with RBD.

Methods In total 94 patients (mean age: $61.9 \pm 12.7$ years, male: $70.2 \%$ ) diagnosed as RBD were examined using detailed clinical histories, the Beck Depression Inventory (BDI), the Epworth Sleepiness Scale (ESS), and nocturnal polysomnography (PSG).

Results The mean BDI score of all patients was $12.4 \pm 10.3$ and $44.7 \%$ of RBD patients showed depressed mood (BDI $>11$ points). Depressed RBD patients were less able to recall enacted dreams than were non-depressed patients (61.9\% vs. $86.5 \%$, p=0.008). Logistic regression analysis showed that failure to recall enacted dreams was significantly associated with depression, after controlling for confounding variables including the respiratory disturbance index and a history of psychiatric disorders (odds ratio $=0.323, \mathrm{p}=0.041$ ).

Conclusion In this study, $44.7 \%$ of RBD patients were found to suffer from depressed mood. And, depression was found to be associated with reduced ability to recall enacted dreams. We suggest that routine evaluation of depression be performed in RBD patients, particularly when failure to recall enacted dreams is evident. We speculate that such failure may be associated with emotional dysregulation or neurodegeneration.

Psychiatry Investig 2016;13(2):227-231
\end{abstract}

Key Words REM sleep behavior disorder, Depression, Dream.

\section{INTRODUCTION}

REM sleep behavior disorder (RBD) is a parasomnia characterized by loss of REM sleep-related muscle atonia and consequent dream enactment during sleep. ${ }^{1} \mathrm{RBD}$ patients are at risk of harming themselves or others during dream enactment. ${ }^{2}$ RBD is known to be associated with other neurodegenerative diseases such as Parkinson's disease (PD) and Lewy body dementia. ${ }^{3}$ Additionally, psychiatric symptoms, such as anxiety and alexithymia, are known to be associated with RBD. ${ }^{4,5}$ Therefore, RBD treatment should focus not only on symptom resolution but also on the evaluation and treatment of comorbid disorders.

Unlike anxiety and alexithymia, no consensus has been

Received: June 4, 2015 Revised: August 31, 2015

Accepted: September 9, 2015 Available online: October 19, 2015

$\triangle$ Correspondence: Do-Un Jeong, $\mathrm{MD}, \mathrm{PhD}$

Department of Psychiatry and Center for Sleep and Chronobiology, Seoul National University Hospital, 101 Daehak-ro, Jongno-gu, Seoul 03080, Republic of Korea

Tel: +82-2-2072-2294, Fax: +82-2-744-7241, E-mail: jeongdu@snu.ac.kr

(a) This is an Open Access article distributed under the terms of the Creative Commons Attribution Non-Commercial License (http://creativecommons.org/licenses/bync/3.0) which permits unrestricted non-commercial use, distribution, and reproduction in any medium, provided the original work is properly cited. reached on the relationship between depression and RBD. Some studies have claimed that depression is not associated with $\mathrm{RBD},{ }^{6}$ but one study revealed a tendency for RBD to be associated with depression. ${ }^{5}$ Old age and neurodegenerative disorders are risk factors for both RBD and depression ${ }^{7-9}$ and may support the hypothesis that RBD is associated with depression.

In support of this idea, a recent case control study showed that patients with idiopathic RBD were more likely to report comorbid depression than were controls. ${ }^{10}$ However, this recent study was limited in that only histories of physician-diagnosed depression were assessed, and it ignored the possibility that some depressed RBD patients had not been diagnosed. To our knowledge, no reported study has addressed factors associated with depression in RBD patients.

In this study on RBD patients, we examined the relationship between depression (and associated factors) and RBD.

\section{METHODS}

\section{Subjects}

In total $94 \mathrm{RBD}$ patients (mean age: $61.9 \pm 12.7$ years, males: 
$70.2 \%)$ were included and their clinical and laboratory data were collected. These data were obtained between January, 2010 and May, 2014 at the Center for Sleep and Chronobiology, Seoul National University Hospital. The RBD diagnosis was made using the International Classification of Sleep Disorders (second edition; ICSD II) criteria, ${ }^{11}$ based on nocturnal polysomnography (PSG) data. Nocturnal PSGs were conducted and scored by trained technologists using standardized methods, ${ }^{12}$ and the results were finally read by trained sleep physicians. The study protocol was approved by the institutional review board of Seoul National University Hospital.

\section{Measurements}

In $94 \mathrm{RBD}$ patients, medical records, replies to self-report questionnaires and nocturnal PSG data were reviewed. The Beck Depression Inventory (BDI ${ }^{13}$ was used to assess the level of depressed mood in patients diagnosed with RBD. Different BDI cut-off score can be used, i.e., 8 for screening and 16 for diagnosis, so we used a cutoff score of 11 because we sought to assess depressed mood with high sensitivity while avoiding low specificity. ${ }^{14}$ We defined patients with total BDI scores $>11$ as depressed, and those with scores $\leq 11$ as nondepressed. The Epworth Sleepiness Scale (ESS) was used to assess the general level of daytime sleepiness. ${ }^{15}$

We collected relevant clinical characteristics, including age at RBD diagnosis, reported RBD onset-time, history of injury during sleep, recall of enacted dreams, history of psychiatric disorders, history of neurological disorders, and any family history of RBD.

\section{Statistical analyses}

Statistical analyses were performed using the SPSS software (ver. 21). The $\chi^{2}$ and t-tests were used to compare categorical and continuous variables, respectively. Parameters significantly correlated with depressed mood were subjected to logistic regression analysis to determine the variables that re- liably identified patients with depressed mood. The significance level (p) was set at $<0.05$.

\section{RESULTS}

The RBD patients in this study were 66 males (70.2\%) and 28 females (29.8\%). The number of patients with a history of neurological disorders was 10 (10.6\%), including five (5.3\%) patients with Parkinson's disease or Parkinsonism and five (5.3\%) patients with conditions including cerebral stroke and dementia. The number of patients with a history of psychiatric disorders was 18 (19.1\%), including six (6.4\%) patients with mood disorder, five (5.3\%) with anxiety disorder, five (5.3\%) with sleep disorder, and two (2.1\%) patients with other conditions such as alcohol dependence and somatoform disorder. As shown in Table 1, comparisons between male and female patients in terms of clinical characteristics showed no significant differences. Also, BDI and ESS scores did not differ significantly between males and females. Table 2 presents the nocturnal polysomnographic characteristics of study patients and comparisons between male and female patients. The N2 and $\mathrm{N} 3$ sleep percentages were higher in female than in male patients $(49.6 \pm 7.9 \%$ vs. $44.8 \pm 10.7 \%$; $\mathrm{p}=0.036 ; 9.6 \pm 7.3 \%$ vs. $5.3 \pm 6.8 \%$; $\mathrm{p}=0.007$, respectively, all t-tests). Sleep latency and REM latency in female RBD patients were longer than those in males $(22.9 \pm 25.8 \mathrm{~min}$ vs. $10.3 \pm 10.9 \mathrm{~min} ; \mathrm{p}=0.018 ; 140.3 \pm$ $64.6 \mathrm{~min}$ vs. $108.0 \pm 65.9 \mathrm{~min} ; \mathrm{p}=0.031$, respectively, all t-tests). Other PSG parameters did not differ significantly between males and females.

The mean BDI score of all patients was $12.4 \pm 10.3$. Of them, $42(44.7 \%)$ patients were depressed (BDI $>11)$. Depressed RBD patients were less able to recall enacted dreams than were non-depressed ones (61.9\% vs. $86.5 \%$; $\mathrm{p}=0.008, \chi^{2}$ test) (Figure $1)$. As shown in Table 3 , depressed patients had a higher respiratory disturbance index $(17.8 \pm 19.9$ vs. $9.5 \pm 10.2 ; \mathrm{p}=0.017$, t-test) and were more likely to have a history of psychiatric

Table 1. Clinical characteristics of RBD patients $(N=94)$

\begin{tabular}{|c|c|c|c|c|}
\hline Variables & Total $(\mathrm{N}=94)$ & Male $(\mathrm{N}=66)$ & Female $(\mathrm{N}=28)$ & p-value \\
\hline Age at diagnosis (years) & $61.9 \pm 12.7$ & $61.7 \pm 11.8$ & $62.2 \pm 14.6$ & NS \\
\hline Age at reported onset (years) & $57.2 \pm 13.4$ & $57.0 \pm 12.3$ & $57.7 \pm 15.9$ & NS \\
\hline Recall of enacted dreams, N (\%) & $71(75.5)$ & $51(77.3)$ & $20(71.4)$ & NS \\
\hline History of injury during sleep, $\mathrm{N}(\%)^{*}$ & $53(62.4)$ & $35(60.4)$ & $18(66.6)$ & NS \\
\hline History of neurological disorders, $\mathrm{N}$ (\%) & $10(10.6)$ & $8(12.1)$ & $2(7.1)$ & NS \\
\hline History of psychiatric disorders, N (\%) & $18(19.1)$ & $12(18.2)$ & $6(21.4)$ & NS \\
\hline Family history of RBD, $\mathrm{N}(\%)$ & $1(1.1)$ & $0(0.0)$ & $1(3.6)$ & NS \\
\hline BDI score & $12.4 \pm 10.3$ & $11.0 \pm 8.6$ & $15.1 \pm 11.1$ & NS \\
\hline ESS score & $8.1 \pm 4.3$ & $8.5 \pm 4.4$ & $7.1 \pm 3.9$ & NS \\
\hline
\end{tabular}

The values are means \pm standard deviation. ${ }^{*} \mathrm{~N}=85 . \mathrm{p}<0.05$. RBD: REM sleep behavior disorder, BDI: Beck Depression Inventory, ESS: Epworth Sleepiness Scale, NS: not significant 
Table 2. Nocturnal polysomnographic characteristics of RBD patients $(\mathrm{N}=94)$

\begin{tabular}{|c|c|c|c|c|}
\hline Variables & Total $(\mathrm{N}=94)$ & Male $(\mathrm{N}=66)$ & Female $(\mathrm{N}=28)$ & p-value \\
\hline Total sleep time (min) & $409.1 \pm 64.9$ & $409.9 \pm 60.8$ & $407.3 \pm 74.7$ & NS \\
\hline Sleep efficiency (\%) & $81.3 \pm 12.9$ & $82.2 \pm 12.4$ & $79.0 \pm 13.9$ & NS \\
\hline Stage N1 (\%) & $21.4 \pm 14.1$ & $22.4 \pm 10.3$ & $19.3 \pm 20.6$ & NS \\
\hline Stage N2 (\%) & $46.2 \pm 10.1$ & $44.8 \pm 10.7$ & $49.6 \pm 7.9$ & $0.036^{*}$ \\
\hline Stage N3 (\%) & $6.6 \pm 7.2$ & $5.3 \pm 6.8$ & $9.6 \pm 7.3$ & $0.007^{*}$ \\
\hline Stage REM (\%) & $22.4 \pm 9.1$ & $22.7 \pm 9.9$ & $21.5 \pm 6.8$ & NS \\
\hline Sleep latency (min) & $14.0 \pm 17.6$ & $10.3 \pm 10.9$ & $22.9 \pm 25.8$ & $0.018^{*}$ \\
\hline REM latency (min) & $117.6 \pm 66.8$ & $108.0 \pm 65.9$ & $140.3 \pm 64.6$ & $0.031^{*}$ \\
\hline $\mathrm{RDI}(/ \mathrm{h})$ & $13.2 \pm 15.8$ & $13.9 \pm 15.2$ & $11.5 \pm 17.1$ & NS \\
\hline $\operatorname{PLMI}(/ \mathrm{h})$ & $19.8 \pm 24.8$ & $20.2 \pm 23.9$ & $19.0 \pm 27.4$ & NS \\
\hline
\end{tabular}

The values are means \pm standard deviation. ${ }^{*} \mathrm{p}<0.05$. RBD: REM sleep behavior disorder, RDI: respiratory disturbance index, PLMI: periodic limb movement index, NS: not significant

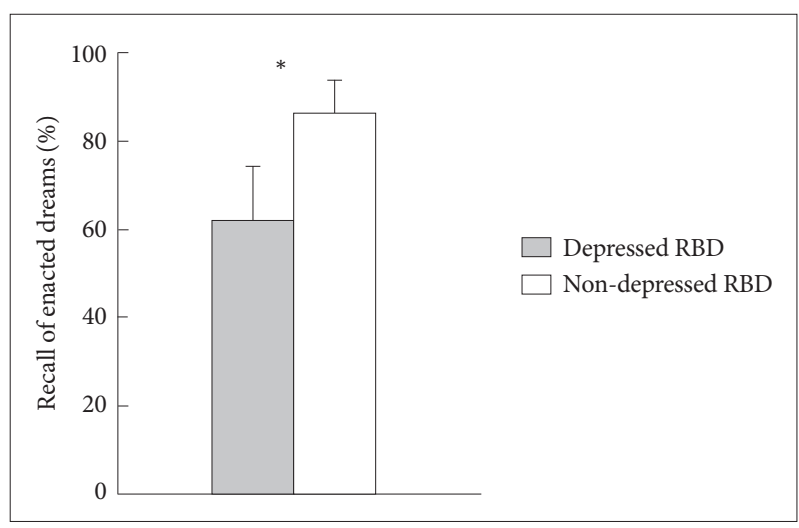

Figure 1. Reduced enacted dream recall in depressed vs. nondepressed RBD. Depressed RBD patients were less able to recall enacted dreams than were non-depressed ones. ${ }^{*} p<0.05$. RBD: REM sleep behavior disorder.

disorders compared with non-depressed RBD ones (31.0\% vs. 9.6\%; $\mathrm{p}=0.016, \chi^{2}$ test). Table 4 shows no significant difference in the PSG study between depressed and non-depressed patients.

As shown in Table 5, after controlling for the respiratory disturbance index and history of psychiatric disorders, the ability to recall enacted dreams was negatively associated with BDI scores higher than 11 (odds ratio $=0.323, \mathrm{p}=0.041$, logistic regression analysis).

\section{DISCUSSION}

We aimed to explore the relationship between depression (and associated factors) and RBD and found that $44.7 \%$ of all RBD patients met the criteria for depression (BDI score $>11$ ). Compared with the prevalence of depression in the general population (21.6\%), ${ }^{16}$ the higher incidence of depression found in this study may be clinically significant. Our finding is also higher than the $28.8 \%$ value from a previous study on RBD patients. ${ }^{10}$ That previous study included only patients who had been diagnosed with depression by physicians, thereby excluding non-diagnosed depressed patients. The enrollment of a higher proportion of female RBD patients in the present study might have affected the prevalence of depression in RBD patients, because females are more likely to be depressed than males ${ }^{17}$ and Our results showed no significant difference between males and females but tendencies toward gender differences in BDI scores and in the percentage of patients with depression were observed ( $\mathrm{p}$-value is 0.06 and $0.07 \mathrm{re}-$ spectively). The data support the hypothesis that patients with $\mathrm{RBD}$ are more likely to be depressed.

It is notable that depressed RBD patients were less likely to recall enacted dreams than were non-depressed patients. Emotional dysregulation is known to trigger failure to recall enacted dreams, because dreams contain emotions. ${ }^{18}$ This study is partially supported by previous studies in which the frequencies of dream recall in alexithymic or depressive subjects were lower than those in non-alexithymic or non-depressed subjects. ${ }^{18,19}$ Taken together, the data show the possibility that RBD patients suffering from emotional dysregulation may become depressed, rendering the recall of enacted dreams less likely.

Neurodegeneration may also explain our present findings. Depression is common in patients with neurodegenerative diseases such as Parkinson's disease, ${ }^{20}$ and RBD is known to be associated with such neurodegenerative disorders. ${ }^{3}$ Depressed RBD patients may have possibility that more neurodegenerative changes than do non-depressed patients, and it could make them less attentive and more memory-impaired. Because of these impairments, depressed RBD patients may become less likely to recall enacted dreams.

A previous study showed that enacted dreams in RBD patients had more content with aggression, such as stranger's attacks, than other forms of parasomnia. These aggressive features in the enacted dreams could be explained by cognitive 
Table 3. Comparison of depressed and non-depressed RBD patients on clinical characteristics $(\mathrm{N}=94)$

\begin{tabular}{|c|c|c|c|}
\hline Variable & Depressed $(\mathrm{N}=42)$ & Non-depressed $(\mathrm{N}=52)$ & p-value \\
\hline Age at diagnosis (years) & $61.2 \pm 15.2$ & $62.4 \pm 10.2$ & NS \\
\hline Age at reported onset (years) & $55.7 \pm 17.3$ & $58.2 \pm 10.0$ & NS \\
\hline Males, N (\%) & $25(59.5)$ & $41(78.8)$ & NS \\
\hline Recall of enacted dreams, N (\%) & $26(61.9)$ & $45(86.5)$ & $0.008^{\dagger}$ \\
\hline History of injury during sleep, $\mathrm{N}(\%)^{*}$ & $20(54.0)$ & $33(68.8)$ & NS \\
\hline History of neurological disorders, N (\%) & $3(7.1)$ & $7(13.5)$ & NS \\
\hline History of psychiatric disorders, N (\%) & $13(31.0)$ & $5(9.6)$ & $0.016^{\dagger}$ \\
\hline Family history of RBD, N (\%) & $1(2.4)$ & $0(0.0)$ & NS \\
\hline ESS & $8.8 \pm 4.4$ & $7.6 \pm 4.1$ & NS \\
\hline $\mathrm{RDI}(/ \mathrm{h})$ & $17.8 \pm 19.9$ & $9.5 \pm 10.2$ & $0.017^{\dagger}$ \\
\hline $\operatorname{PLMI}(/ \mathrm{h})$ & $16.8 \pm 22.7$ & $22.3 \pm 26.4$ & NS \\
\hline
\end{tabular}

The values are means \pm standard deviation. ${ }^{*} \mathrm{~N}=85,{ }^{\dagger} \mathrm{p}<0.05$. RBD: REM sleep behavior disorder, ESS: Epworth Sleepiness Scale, RDI: respiratory disturbance index, PLMI: periodic limb movement index, NS: not significant

Table 4. Comparison of depressed and non-depressed RBD patients on Nocturnal polysomnographic characteristics $(\mathrm{N}=94)$

\begin{tabular}{lccc}
\hline \multicolumn{1}{c}{ Variables } & $\begin{array}{c}\text { Depressed } \\
(\mathrm{N}=42)\end{array}$ & $\begin{array}{c}\text { Non-depressed } \\
(\mathrm{N}=52)\end{array}$ & p-value \\
\hline Total sleep time (min) & $411.9 \pm 67.8$ & $406.9 \pm 63.0$ & $\mathrm{NS}$ \\
Sleep efficiency (\%) & $81.1 \pm 14.3$ & $81.4 \pm 11.8$ & $\mathrm{NS}$ \\
Stage N1 (\%) & $22.1 \pm 18.2$ & $20.8 \pm 9.9$ & $\mathrm{NS}$ \\
Stage N2 (\%) & $47.5 \pm 10.3$ & $45.2 \pm 10.0$ & $\mathrm{NS}$ \\
Stage N3 (\%) & $6.8 \pm 6.2$ & $6.4 \pm 8.0$ & $\mathrm{NS}$ \\
Stage REM (\%) & $21.0 \pm 7.6$ & $23.4 \pm 10.0$ & $\mathrm{NS}$ \\
Sleep latency (min) & $17.7 \pm 23.1$ & $11.1 \pm 10.7$ & $\mathrm{NS}$ \\
REM latency (min) & $122.0 \pm 62.7$ & $114.1 \pm 70.4$ & $\mathrm{NS}$ \\
\hline
\end{tabular}

The values are means \pm standard deviation. $\mathrm{p}<0.05$. RBD: REM sleep behavior disorder, NS: not significant

Table 5. Risk factors associated with depression in RBD patients $(\mathrm{N}=94)$

\begin{tabular}{lcll}
\hline \multicolumn{1}{c}{ Variable } & OR & \multicolumn{1}{c}{$95 \%$ CI } & p-value \\
\hline Recall of enacted dreams & 0.33 & $0.11 \pm 0.95$ & $0.041^{*}$ \\
History of psychiatric disorders & 4.74 & $1.44 \pm 15.60$ & $0.011^{*}$ \\
RDI & 1.04 & $1.00 \pm 1.07$ & $0.029^{*}$
\end{tabular}

The values are means \pm standard deviation. ${ }^{*} \mathrm{p}<0.05$. RBD: REM sleep behavior disorder, RDI: respiratory disturbance index, OR: odds ratio, CI: confidence interval

dysfunction, particularly frontal dysfunction. ${ }^{21}$ Thus, enacted dreams in RBD may have clinical importance in predicting the possible onset of neurodegeneration.

This study included a higher proportion of female RBD patients than did a previous study, in which females accounted for $18 \%$ of the RBD patients. ${ }^{7}$ The previous study reported that clinical histories or questionnaire responses alone were less sensitive than PSG for detecting RBD in females. ${ }^{22}$ In the present study, we used both history and nocturnal PSG diag- nostically to avoid underdiagnosing RBD. The inclusion of nocturnal PSG may explain why the proportion of female RBD patients in this study was higher than that in the previous study. ${ }^{22}$ In PSG findings, the percentages of N2 and N3 sleep and REM latencies differed significantly between male and female RBD patients. These differences were similar to those reported in a previous study on gender differences in PSG. ${ }^{23}$ Theses finding were also similar to a recent study on gender differences in China based on polysomnographic findings. ${ }^{24}$

This study has several limitations. First, it was cross-sectional and retrospective. We were not able to identify any causal relationship between enacted dream recall and depression in RBD. Second, we assessed depression using only the BDI. More reliable results might have been obtained if depression had been diagnosed using the Diagnostic and Statistical Manual for Mental Disorders, fifth edition (DSM-5) ${ }^{25}$ or the Structured Clinical Interview for DSM-IV-TR Axis I Disorders (SCID). ${ }^{26}$ Third, enacted dream recall was assessed using a single question. More reliable data might have been obtained by examining detailed features of enacted dream recall, such as frequency, number of dreams and dream contents. Fourth, there could be other confounding factors that were not assessed in this study, such as medication use. The study sample has may include patients with secondary RBD, such as that due to antidepressant use or Parkinsonism. Finally, associations between enacted dream recall and cognitive disturbance were not studied

In summary, we found that about half of all RBD patients met our depression criteria. These depressed RBD patients were less likely to recall enacted dreams than were non-depressed ones. It may be important to carefully examine mood in RBD patients to detect depressive symptoms in a timely manner. 


\section{REFERENCES}

1. Schenck CH, Bundlie SR, Ettinger MG, Mahowald MW. Chronic behavioral disorders of human REM sleep: a new category of parasomnia. Sleep 1986;9:293-308.

2. Siclari F, Khatami R, Urbaniok F, Nobili L, Mahowald MW, Schenck CH, et al. Violence in sleep. Brain 2010;133:3494-3509.

3. Boeve BF, Silber MH, Ferman TJ, Lucas JA, Parisi JE. Association of REM sleep behavior disorder and neurodegenerative disease may reflect an underlying synucleinopathy. Mov Disord 2001;16:622-630.

4. Godin I, Montplaisir J, Gagnon JF, Nielsen T. Alexithymia associated with nightmare distress in idiopathic REM sleep behavior disorder. Sleep 2013;36:1957-1962.

5. Molano J, Boeve BF, Roberts R, Geda YV, Knopman D, Tangalos E, et al. Anxiety and apathy are associated with probable REM sleep behavior disorder among cognitively normal elderly subjects: the Mayo clinic study of aging. Neurology 2008;70(Suppl 1):A146.

6. Postuma RB, Lang AE, Massicotte-Marquez J, Montplaisir J. Potential early markers of Parkinson disease in idiopathic REM sleep behavior disorder. Neurology 2006;66:845-851.

7. Wing YK, Lam SP, Li SX, Yu MW, Fong SY, Tsoh JM, et al. REM sleep behaviour disorder in Hong Kong Chinese: clinical outcome and gender comparison. J Neurol Neurosurg Psychiatry 2008;79:1415-1416.

8. Beekman AT, Copeland JR, Prince MJ. Review of community prevalence of depression in later life. Br J Psychiatry 1999;174:307-311.

9. Reijnders JS, Ehrt U, Weber WE, Aarsland D, Leentjens AF. A systematic review of prevalence studies of depression in Parkinson's disease. Mov Disord 2008;23:183-189.

10. Frauscher B, Jennum P, Ju YE, Postuma RB, Arnulf I, Cochen De Cock $\mathrm{V}$, et al. Comorbidity and medication in REM sleep behavior disorder: a multicenter case-control study. Neurology 2014;82:1076-1079.

11. American Academy of Sleep Medicine. The International Classification of Sleep Disorders: Diagnostic and Coding Manual, ICSD-2. Westchester, IL: American Academy of Sleep Medicine; 2005.

12. Iber C, Ancoli-Israel S, Chesson AL Jr, Quan SF; for the American Academy of Sleep Medicine. The AASM Manual for the Scoring of Sleep and Associated Events: Rules, Terminology and Technical Specifications. 1st Ed. Westchester, IL: American Academy of Sleep Medicine; 2007.

13. Beck AT, Steer RA, Carbin MG. Psychometric properties of the Beck Depression Inventory: twenty-five years of evaluation. Clin Psychol Rev 1988;8:77-100.
14. Leentjens AF, Verhey FR, Luijckx GJ, Troost J. The validity of the Beck Depression Inventory as a screening and diagnostic instrument for depression in patients with Parkinson’s disease. Mov Disord 2000;15:12211224.

15. Johns MW. A new method for measuring daytime sleepiness: the Epworth sleepiness scale. Sleep 1991;14:540-545.

16. Jylha P, Isometsa E. The relationship of neuroticism and extraversion to symptoms of anxiety and depression in the general population. Depress Anxiety 2006;23:281-289.

17. Kuehner C. Gender differences in unipolar depression: an update of epidemiological findings and possible explanations. Acta Psychiatr Scand 2003;108:163-174.

18. De Gennaro L, Ferrara M, Cristiani R, Curcio G, Martiradonna V, Bertini M. Alexithymia and dream recall upon spontaneous morning awakening. Psychosom Med 2003;65:301-306.

19. Armitage R, Rochlen A, Fitch T, Trivedi M, Rush AJ. Dream recall and major depression: a preliminary report. Dreaming 1995;5:189.

20. Raskind MA. Diagnosis and treatment of depression comorbid with neurologic disorders. Am J Med 2008;121(11 Suppl 2):S28-S37.

21. Uguccioni G, Golmard JL, de Fontréaux AN, Leu-Semenescu S, Brion A, Arnulf I. Fight or flight? Dream content during sleepwalking/sleep terrors vs. rapid eye movement sleep behavior disorder. Sleep Med 2013; 14:391-398.

22. Bodkin CL, Schenck CH. Rapid eye movement sleep behavior disorder in women: relevance to general and specialty medical practice. J Womens Health (Larchmt) 2009;18:1955-1963.

23. Silva A, Andersen ML, De Mello MT, Bittencourt LR, Peruzzo D, Tufik S. Gender and age differences in polysomnography findings and sleep complaints of patients referred to a sleep laboratory. Braz J Med Biol Res 2008;41:1067-1075.

24. Zhou J, Zhang J, Li Y, Du L, Li Z, Lei F, et al. Gender differences in REM sleep behavior disorder: a clinical and polysomnographic study in China. Sleep Med 2015;16:414-418.

25. American Psychiatric Association. Diagnostic and Statistical Manual of Mental Disorders, Fifth Edition (DSM-5). Washington, DC: The American Psychiatric Association; 2013.

26. First MB, Spitzer RL, Gibbon M, Williams JB. Structured clinical interview for DSM-IV-TR axis I disorders, research version, patient edition (SCID-I/P). New York: Biometrics Research, New York State Psychiatric Institute; 2002. 